\title{
Role of Medical Committee Resolve Lawsuits at Hospital Covid-19 Pandemic Era
}

\author{
Johanna Marudur Marpaung ${ }^{1}$, Rineke Sara ${ }^{2}$ \\ \{dr.johanna@yahoo.com¹, rineke_sara@borobudur.ac.id² \\ Universitas Borobudur, Jakarta, Indonesia ${ }^{1,2}$
}

\begin{abstract}
Health is human rights accordance with the constitution of Indonesia in 1945 the form of improve to general welfare. Regulation minister of health Indonesian number 755/PER/IV/2011 is about performance medical committee at hospital chapter 1 verse $1^{\text {st }}$ declare medical committee is tools of hospital to do clinical governance that medical staff at hospital to keep professionalism through credential mechanism, quality control of medical profession and ethical maintenance and medical professional discipline. The goal of research to health service at pandemic keep going well. This research use to description, data obtained by medical committee and had been medical audit by professional audit subcommittee accordance chapter 10 verse $2^{\text {nd }} B$ said that: on duty to keep competence and medical staff professionalism. The most complain and lawsuits are patient dissatisfaction to health service. Getting better health service so patient satisfaction against health increase (directly proportional). Patient dissatisfaction or patient's family to service health at pandemic era give rise to many complain even up to do lawsuits to hospital as health care provider.
\end{abstract}

Keywords: Medical committee; Lawsuits; Patient satisfaction

\section{Introduction}

Health is good health include physical, mental, spiritual or social which allow each people to productive life by social and economical. Health is human rights and one element the welfare accordance with the constitution of Indonesia in 1945. Health care facilities are tools or place which used to organize health care there is promotive, preventive, curative and rehabilitative which is conducted by central government, local government and public. Hospital is health care institution who organizes individual health care with plenary to prepare inpatient service, outpatient service and emergency.

Medical committee is hospital device for apply clinical governance so that the hospital medical staff keep professionalism through the credential mechanism, maintenance of the quality of the medical profession, ethical maintenance and medical professional discipline. Medical committee created with a purpose to organize good clinical governance so that the quality of medical services and patient safety is more guaranteed and protected.

Health care service in era pandemic covid-19 is different with before. Many Risk of covid-19 at health care facilities as :

a. High risk infected for health worker 
b. Crisis personal protective equipment (PPE)

c. Risk and crisis management

d. Risk infected for the other patient

e. Crisis financial

Although the situation was not conducive because confusions with the new disease attack people in the world, but hospital management will keep watch the patient safety first, although it isn't easy to practice at hospital by health worker in Indonesia maybe in the other country. Many country almost the same experience which faced like in Indonesia. Maybe can say that shake the world. Many people can receive the situation, but many others cannot. So if the health care service was different with the usually patient or patient's family received before, they will complaint, although had been excellent serviced.

\subsection{Problem Statement}

Community's need for health is increasing in line with the economic improvement in the community because ability to pay the health service achieved by the community. Healty is center for development and well-being. Patient or patient's family wishes extra for health care service with covid-19 pandemic era. They don't know what faced of hospital management and health worker at covid-19 pandemic era. Some of the complaint can finish by give clarification from hospital management, but many used lawyer for finished the complaint.

Hospital management and health worker disturbed because right now very heavy workload at pandemic era. Hospital management had been tool to faced management complaint. The role of medical committee very important because the duty of medical committee was keep professionalism medical staff at hospital. Medical committee consists of medical staff. Medical staff is general practitioner, dentist, medical specialist, dental specialist wich worker at hospital. Medical staff had been busy to care serve the patient who infected covid-19 and increase must to do some of medical audit. After medical committee finished to did medical audit, the result of medical audit will give to hospital management. So, hospital management can explain with patient or patient's family about health condition. Effective communication can reduce complaint or lawsuits. The condition covid-19 pandemic era this moment is not easy, especially for health worker. There is some factor to influence such as :

a. Over load at the work

b. Risk to influence of covid-19

c. Changing work environment

d. Working must use personal protective equipment

e. Increased working time

f. No guarantee of protection

g. Pressure from public

Health worker must do it by self to make comfortable at working. Supported from health worker to other health worker very important, also supported from health worker's family. Time by time is over can make public to know the situation covid-19 pandemic, but it is not make automaticly to understood. It is still need time to give more information to the public because they was got wrong information about covid-19 pandemic. It is make they does not belive to health worker or hospital. They are mostly believe to hear wrong information/hoax than the true information. Sometimes, they denial for the situation covid-19 pandemic.

Pandemic situation made changing for all life pattern in the world. Covid-19 pandemic was scared because : the new disease, fast transmission and cause death. Covid-19 pandemic era was made mental disorder for some people. 


\subsection{Literature Review}

Corona virus disease 2019 (Covid-19) is infectious diseases by severe acute respiratory syndrome Coronavirus 2 (SARS-CoV-2). SARS-CoV-2 came from group the same virus with SARS's virus and MERS. The different between SARS-CoV-2 from MERS-CoV on neuraminidase enzyme. The first time reported for corona virus disease at December in Wuhan, China. In Indonesia reported at $2^{\text {nd }}$ March 2021 for the first cases covid-19, later government announces and set as national disaster-not natural.

Corona virus disease 2019 (Covid-19) become international problem after spread to almost all country, so that world health organization (WHO) determine as covid-19 pandemic era. All of country in the world make efforts to handle covid-19. It isn't easy to handle covid-19. Covid-19 had been killing many people in the world. The death of health worker in Indonesia highest compared to the other country. Some problem faced the health care service at hospital in Indonesia which almost same with the other country. There is some problem happened at work environment, beside the other problem such as :

a. Lack of infrastructure at health care service

b. Lack of diagnostic test for corona virus disease (real time reserve transcription polymerase chain reaction/RT-PCR).

c. Deficient for personal protective equipment (PPE).

d. Health care service (hospital) doen't enough for accommodate/treating patients.

e. Deficient for HCU (high care unit) or ICU (intensive care unit)

The problem upon caused obstructed to handle covid-19 patient, also become cause spread covid-19 increase, especially to health worker. So that the death health worker highest to compare to the other country in the world. Also with health worker in Indonesia some old age, it makes susceptible to infected covid-19, then government prohibit for health worker have old age in order not to practice, it strategy medical safety and protection for health worker. The old age can practice with the way telemedicine. Cut off for old age is on $60^{\text {th }}$ years.

There still is the other problem, it makes patient and patient's family fells unsatisfied for health care service. Some of them unbelieve to health worker because they denial infected covid-19, even if the diagnostic's result to showed it. Sometimes, patient's family accuses health worker purposeful to diagnostic covid-19 to get benefits. Nevertheless, health worker keeps working with the principles safety patient with responsibility.

With limitation and pandemic conditions, health worker must keep the spirit to against covid-19 to help Indonesia out from covid-19 pandemic because it has damaged many sector. Supported between health worker can help their sprit, it seems in handling covid-19 patient.

\section{Research Methods}

This research is using qualitative method. Data took for this research with using secondary data. Secondary data had got management complaint and reported from medical committee at hospital. The location of this study did at one of privat hospital, at central Jakarta, Indonesia. This research was started at April 2020 until September 2021.

Researchers in this study, uphold research ethics. This research data protected from misuse, confidentiality and scientific attitude. It is important for me as researcher. This study is using to scientific interest. There is four principles of research ethics (Milton, 1999 in Notoatmodjo, $2010: 203$ ), as :

a. Respect for human dignity. 
b. Respect for privacy and confidentiality.

c. Respect for justice and inclusiveness.

d. Balancing harms and benefits.

This research data analysis technique used to complaint report by written and oral which exists at medical committee. All of data had been stored and documented at medical committee. Techniques to unsure the validity of the data by validation. Validation based on certainty what to result of this study had accurate from researcher or observer. Strategy of validation by used triangulate, based on multi perspective. Function triangulate is avoid to use thoughts from researchers.

\section{Analysis and Discussion}

The condition of covid-19 pandemic had been made changing daily life pattern for human. Health care service at pandemic era become to be hardest. For the beginning the patient enterance to the hospital, administration section was explained for the regulation at hospital. After the family patient understood the regulation so will be asking to sign general concent. Inpatient also given the information to patient's family about condition daily of patient. Patient's family which received information routine everyday, rarely complaint or lawsuits. The problem is patient's family who come not everyday so receive minimal information patient's condition. With minimal information can make misunderstanding and than angry if condition of patient was not good.

Besides give information about patient's condition, give information about administrative regulations also important. There are different regulation for covid patient, so it is important to explaint to patient's family. Administrastive regulation is often change along with regulatory changes by government. Government's regulation is important because patient's payment did by government. Regulator changes also needs more time to socialization to administrative officer. It is important because it will the beginning information will give to patient's family when patient's family to sign general concent at section administrative.

In term of administrative regulation had many problem. The most problems for administrative regulation are:

a. Payment guarantee

b. Burial of corpses

c. Patient's waiting

d. Patient's procedure for returning home care

e. Requirements for hospitalization.

The way for avoid the complaint or lawsuits from patient or patient's family, there are many way. Hospital had been regulation to manage complaint, we called it with "management complaint." Complaint increases at Pandemic era. Many cases at medical committee as:

a. Dissatisfaction to health care service

b. Patient's family feels misdiagnose (rejeck for covid-19 diagnose)

c. Rejeck to cemetery by procedure infectious disease.

To handling complain dan lawsuits, medical committee had been guideline. The first, the director sends letter to medical committee to inform that cases. Then, medical committee done medical audit. After finished medical audit, so medical committee sent to the director result of medical audit. On the basis of recommendation medical can help to finished. There are some cases need more time, depending the cases. Example : the case had met at peer group, but that case still need second opinion or third opinion from the other peer group. It will need more 
time to disccuss it. It is usually difficult case with crisis condition. Many the cases had been handle as outpatient with need strict observation at high care unit (HCU) or with condition patient's crisis at intensive care unit (ICU).

Sometimes, the cases doesn't finish until that. Patient's family still asking the lawyer to lawsuits. Management complaint, director and the lawyer of hospital will invite the lawyer's patient and patient's family to do medition. For this moment, some the cases finished. Until now, not yet the cases brings to the court.

\section{Conclusion}

After post research, finally researcher made conclusion for this research. There are 2 type case reason for patient or patient's family complain or lawsuits:

1. Patient's medical condition.

2. Administrative regulation for covid-19 patient.

Problem solving for patient's medical condition (point one), there is involve medical committee but for administrative regulation for covid patient (point two) doesn't involve medical committee. It will handle by management complaint officer if the category cases mild until moderate. But severe category cases, it will handle by medical director at hospital. Conclusion as :

a. Patient's family must receive routine information.

b. Signer general concent

c. Do standart procedure operation (SPO) and clinical pathway (CP).

d. Do medition

To avoid complaint and lawsuits from patient's family even point one and two, all of them need effective communication. It is starting for the beginning patient enter at emergency room or policlinic and for patient's family at admission office. So it is important to management's hospital to training all of the staff to do excellent services.

\section{References}

[1] Communion of Churches in Indonesia (CCI) Cikini, hospital. Management complain guideline. Jakarta (2017)

[2] Lumenta, Nico A. Patient safety : price off. Rayyana komunikasindo, Jakarta (2021)

[3] Minister of health, regulation by number 36. 2009. Health. Jakarta, Indonesia.

[4] Minister of health, regulation by number 44. 2009. Hospital. Jakarta, Indonesia.

[5] Minister of health, regulation by number 755. Organizing medical committee. Jakarta, Indonesia (2011)

[6] Minister of health, regulation by number 4344. Technical instructions reimbursement claim corona virus disease 2019 (covid-19) patient service for hospital as organizer corona virus disease 2019 (covid-19) service, Jakarta, Indonesia (2021)

[7] Minister of health, regulation by number 5671. 2021. Clinical management corona virus disease 2019 therapy at health care service. Jakarta, Indonesia.

[8] Minister of health, regulation by number 3602. Utilization rapid diagnostic test antigen under inspection corona virus disease 2019 (Covid-19). Jakarta, Indonesia (2021)

[9] Millton, C.L. Ethical issues from nursing theoretical perspectives. Nursing science quarterly (1999) 
[10] The Indonesian medical association. Guidelines doctor protection standart at corona virus disease 2019 (Covid-19) pandemic era, Edition 3rd. The Indonesian medical association central executive board, Jakarta (2021)

[11] World health organization. 2020. Diagnostic testing for SAR Covid-2 (Interim guidance). 